\title{
A escrita de protesto de Tenzin Tsundue - pelo Tibete livre
}

Gisele Wolkoff

Resumo: As traduções que aqui apresentamos pretendem introduzir o poeta Tenzin Tsundue ao contexto de língua portuguesa, a partir de dois poemas significativos da experiência do exílio na Índia e da luta pelo Tibete independente, além do texto autobiográfico "My Mumbai Story", "A Minha Estória de Mumbai".

Palavras-chave: Exílio; Tibete; Índia; Independência

\begin{abstract}
The translations that follow attempt to introduce the poet Tenzin Tsundue to the context of the Portuguese language, from two of his poems that are relevant as regards the experience of exile in India, as well as the struggle for an independent Tibet, together with his autobiographic text entitled "My Mumbai Story".
\end{abstract}

Keywords: Exile; Tibet; India; Independence 


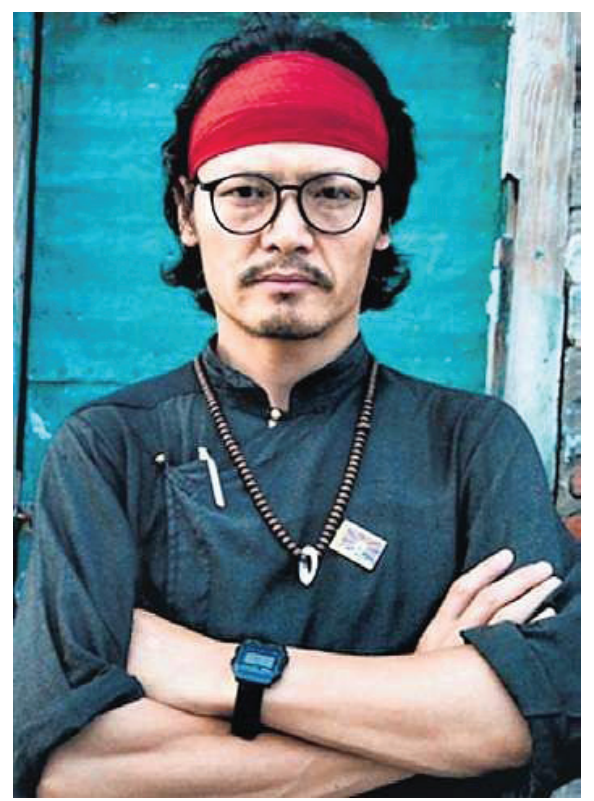

O Oriente tem vindo a despertar crescente interesse nos estudiosos e no vasto público ocidental, particularmente, a partir das últimas décadas do século XX, pela disseminação de cultura popular e da popularização das culturas milenares que compõe. Assim, geografias distantes e pouquíssimo conhecidas como o Tibete rondam o mistério que precisa ir se desvelando para além dos estereótipos da cultura popular. É assim que os poemas e as narrativas de Tenzin Tsundue nos guiam de maneira realista, pelas mãos de alguém que nasceu nas montanhas, de pais tibetanos exilados na Índia e trabalhadores nas construções de estradas nas montanhas. Educado em Dharamsala, tem vindo a se dedicar à causa tibetana desde os tempos de faculdade, quando escreveu Crossing the Border, publicado em 1999, Semshook: Essays on the Tibetan Freedom Struggle, em 2007 e Tsengol: Stories and Poems of Resistance, 2012.

Os poemas e prosa que aqui trazemos falam da angústia de ser um exilado e de se perder de vista o tempo do retorno, que se mostra impossível não fosse a luta política com as palavras. Eles constam do livro Kora: stories and poems, cuja primeira edição data de 2002 mas a que utilizamos é de 2010. E o texto "A Minha Estória de Mumbay" apareceu na quarta edição de 2006. Nada vamos falar dos poemas, pois vamos deixá-los conduzir o leitor ao lirismo único, pessoal e, tam- 
bém, social da voz que os canta. Entretanto, convém apontarmos os desafios de traduzir um contexto quase totalmente a nós do mundo lusófono desconhecido.

A primeira grande questão que se nos apresenta é como traduzir o dilema Mumbay-Mumbai-Bombay. Claramente, o nome da grande capital indiana com " $y$ " ao final deve ser uma reapropriação de Tenzin Tsundue ele mesmo e que decidimos manter pois nos oferece múltiplas acepções - da influência estrangeira, inglesa à carga de afeto que leva a todos os envolvidos, seja na estória contada pelo autor, seja na imaginação que se vai construindo pelos leitores, na dinâmica da cidade. No mais, sabemos que o nome Mumbai descende da deusa Mumba, divindade dos pescadores e agricultores e que se vai modificando para Bombay (ou, Bombaim, em português dicionarizado) pela provável percepção que os imperialistas faziam de uma cidade que se desenvolvia ao longo da "boa bahia". De todos os modos, procuramos manter o uso do autor, ora "Mumbai", ora "Bombay" e, com a exceção do título, o nome aparece com "y"!

$\mathrm{Na}$ senda da falta de conhecimento ocidental acerca do Oriente, "My Mumbay Story" nos brinda com termos como "Losar" (ano novo tibetano"), "vadapão", "goondas" (que uma rápida busca em portais da rede mundial nos traz duplas acepções que cabem perfeitamente na construção semântica do leitor) "chawl" (conglomerados próximos de "favelas") "chalta hai" (que entendemos melhor seria deixar um termo próximo na língua portuguesa, “despreendidos"). Mas ficamos na imaginação dos sons, da pronúncia citada pelo autor da palavra "Mumbai" no "sotaque mediano". E sentimos a dor e a alegria de se poder falar cada qual de um jeito, ouvimos o "apedrejamento espiritual" silencioso dos nativos aos que falam um "sotaque mediano", porque isso é universal. Como já bem declarou a poeta portuguesa Ana Luísa Amaral "Em toda a parte, as mesmas coisas são." (em seu poema Lugares Comuns). Só que há lugares de que não se têm notícia, ou se têm muito pouca notícia - é o caso do Tibete. E aí é preciso dizer, enunciar, gritar ao mundo a imposição do silêncio, quebrá-lo com as Artes. Eis o trabalho de Tenzin Tsundue.

E porque traduzir é transculturar, ir para além das geografias e nos desencontros delas, onde elas certamente convergem, escolhemos grafar o adjetivo Tibetano que, pela norma da língua portuguesa, deveria vir com letra minúscula, com a maiúscula, relocando o espaço do Tibete ao centro do mundo e do Tibetano, no coração da Luz - numa breve desrreferência à narrativa de Joseph Comrad, Heart of Darkness (Coração das Trevas). Assim, compactuamos da liberdade de uma Terra e de seu Povo, quando todas as terras e os povos já deveriam ser livres... 


\section{Refugee}

When I was born

My mother said

you are a refugee.

Our tent on the roadside

smoked in the snow.

On your forehead

between your eyebrows

there is an $\mathbf{R}$ embossed

my teacher said.

I scratched and scrubbed, on my forehead I found a brash of red pain.

I am born refugee.

I have three tongues.

The one that sings

is my mother tongue.

The $\mathbf{R}$ on my forehead

between my English and Hindi

the Tibetan tongue reads:

\section{RANGZEN}

Freedom means Rangzen 


\section{Refugiado}

Quando nasci

Minha mãe disse

você é um refugiado.

A nossa barraca na estrada, evadida na neve.

Na sua testa

entre as sobrancelhas

tem um $\mathrm{R}$ gravado

minha professora quem disse.

Cocei \& esfreguei

e na minha testa encontrei

uma mancha vermelha de dor.

Nasci um refugiado.

Tenho três línguas.

Aquela na qual canto

é a minha língua-mãe.

O $\mathbf{R}$ na minha testa

entre o Inglês e o Hindi

a língua Tibetana revela:

\section{RANGZEN}

A liberdade significa Rangzen. 


\section{Exile House}

Our tiled roof dripped

and the four walls threatened to fall apart

but we were to go home soon.

We grew papayas

in front of our house

chillies in our garden

and changmas for our fences,

then pumpkins rolled down the cowshed thatch

calves trotted out of the manger.

Grass on the roof,

beans sprouted and

climbed the vines,

money plants crept in through the window,

our house seems to have grown roots.

The fences have grown into a jungle,

now how can I tell my children

where we came from? 


\section{A casa do exílio}

O nosso telhado ladrilhado gotejou

e as quatro paredes ameaçaram desabar

mas estávamos prestes a retornar ao lar.

Plantamos mamão

em frente à casa

pimenta, em nosso jardim

e changma* para as nossas cercas

daí, as abóboras começaram a rolar pela palha do estábulo

que os bezerros jogaram pra fora da manjedoura.

A relva no telhado

os grãos que brotaram e

escalaram as videiras

as plantas jade se esparramaram pela janela

e a nossa casa parece ter dado raízes.

As cercas tornaram-se uma floresta, e agora como posso dizer aos meus filhos de onde viemos?

* Changma tem uma polissemia no contexto tibetano: refere-se tanto ao bambu, tipos de madeira que podem ser usados em cercas, como também tristeza, dor, sofrimento. 


\section{A minha estória de Mumbay}

Vim à Mumbai para fugir da comunidade Tibetana. Em 1997, eu tinha ido ao Tibete sem documentos e fui preso pela polícia chinesa de fronteira. Depois de três meses de espancamentos, humilhação e tortura mental na prisão, fui expulso do Tibete. Ao invés de me apoiarem, os meus parentes na India ralharam comigo e me repreenderam por eu não os ter informado que iria antes de o fazer. Gritaram comigo porque os levei a grande estresse mental - não tendo compreendido o que eu experienciei por ter sobrevivido à brutalidade policial e ao interrogatório por meses na prisão.

Mumbai não é um conglomerado típico. Há pouco mais de trinta Tibetanos vivendo na cidade, trabalhando de maneira ímpar como em restaurantes, ou na produção de massa de macarrão e, hoje em dia, jovens na área de T.I. Durante o inverno, cerca de duzentos Tibetanos vêm à cidade para vender agasalhos: depois de uma estada de dois meses, feito pássaros migratórios, eles retornam aos seus campos de refugiados para celebrar o Losar, o Ano Novo Tibetano do calendário lunar que costuma cair em fevereiro. A chegada dos vendedores de agasalhos tibetanos é vista como um prenúncio do inverno na cidade que, de outro modo, tem apenas duas estações - o verão e a estação das chuvas.

Quando venho à Bombai, Rani Mukherjee, em painéis promocionais de grandes filmes, sorri para mim. Para simples Tibetanos, Bombai é uma cidade lendária e onírica que viram nos filmes de Amitabh Bachchan. Eis a cidade grande, com farto dinheiro e um monte de goondas. Também é conhecida por seus atores de Bollywood. Assim, com frequência, pedem-me para trazer fotos reais de Aamir Khan e Aishwarya Rai ao pessoal. Os Tibetanos médios ainda não entenderam a confusão que é chamar a cidade de Bombai. Então, os Tibetanos pronunciam-na com um sotaque mediano - 'Mumbai'.

Os primeiros Tibetanos chegaram quando isso ainda era Bombai, no começo dos anos 1950, quando o Tibete ainda era um país independente. Os Tibetanos que se estabeleceram em Darjeeling e Kalimpong costumavam frequentar a cidade portuária mais próxima, Calcutá. No entanto, três famílias Tibetanas vieram à Bombai junto com chineses que haviam fugido da China depois da revolução comunista de 1949. Eram amigos nos negócios de fabricação de macarrão.

Mesmo hoje, alguns dos melhores restaurantes e hotéis em Mumbai abastecem-se de macarrão das pequenas fábricas Tibetanas da cidade. Cerca de vinte jovens trabalham como cozinheiros nos restaurantes "chineses". Kunga, quarenta anos, que treinou cerca de trinta Tibetanos jovens neste negócio, certa 
vez respondeu a um jornalista acerca dessa aparente contradição política. Eis a sua explanação: "cozinhar é uma habilidade, seja Tibetana, chinesa ou indiana do sul."

Existe uma anedota lendária sobre os primeiros Tibetanos que vieram à Bombai. A estória diz que um grupo deles sentou-se na parte superior de um onibus de dois andares. $\mathrm{O}$ ônibus começou a rugir e estava prestes a se mover. Foi quando o grupo de Tibetanos correu para baixo. O condutor perguntou qual era o problema. Todos gritaram unissonamente: "Não há motorista lá em cima, mas o ônibus está andando." Se essa estória é ou não verdade, não sei, mas circula entre os Tibetanos até hoje. E é para provar que os Tibetanos são observadores e gostam de confirmar tudo.

É tão alegre poder falar e rir em Tibetano na cidade cosmopolita que é Mumbai. Em raras ocasiões como no aniversário da Vossa Santidade Dalai Lama, os poucos Tibetanos morando em Mumbai reunem-se para cantar, dançar e comer boa comida Tibetana. Alguém surge cantando uma canção das montanhas no meio do barulho do trânsito e uma estridente música de filme de Bollywood pode ser ouvida num dos típicos conglomerados indianos (denominados chawl). Levamos os convidados Tibetanos ao Passeio Maritimo a fim de lhes mostrar o quão vasto é o mar, enquanto que nos trens locais de Mumbai, durante as horas do rush, instigamos novos imigrantes a se juntarem a nós para que morem na cidade.

Além de fugir, vim para cá para avançar nos estudos. Ao mesmo tempo em que estudava Literatura e Filosofia no campus Kalina da Universidade de Bombai, foi aqui que comecei a escrever. Passei a conhecer escritores e artistas consagrados como Dom Moraes, Nissim Azekiel, Adil Jussawala e Arun Kolhatkar e inspirei-me em suas artes e pela maneira como lidavam com as suas produções. Também aprendi muito sobre performances de palco, belas artes e o mercado das exposições, os bastidores da cinematografia, bem como sobre relações midiáticas.

Trabalhei muito durante esses anos. Não tinha onde ficar, pois não tinha dinheiro. Acampava nas casas dos amigos em Andheri, Borivli, Cuffe Parade, Santacruz e Amboli. Comutar à cidade a partir de Borivli, lutar por um espaço no trem local de Virar-Churchgate eram um desafio diário. Certa ocasião, quase caí fatalmente durante a hora do rush, no entanto me surpreendi ao perceber que estava lutando pelo mesmo lugar no trem local no dia seguinte ao ocorrido. Sobrevivi com vada-pao, dia após dia, também comendo amendoim no Passeio Marinho, enquanto lamuriava em versos. 
Depois de um mestrado pela Universidade de Bombai, publiquei o meu primeiro livro de poemas com a ajuda de meus colegas de sala que fizeram de tudo para custear o feito. Mais tarde, vendemos cópias do mesmo em faculdades e em sessões de leitura poética na Crossword, Teatro Prithvi, NCPA e no Poetry Circle. Em 2001, ganhei o primeiro Concurso de Ensaios Outlook-Picador All India. Uma vez que naquela época eu morava em Mumbai, a mídia reportou: "Estudante de Mumbai vence concurso de ensaio". Fiquei feliz em ser aceito como um Mumbainte.

Eu era o único Tibetano num campus universitário. E sentia falta da companhia de Tibetanos, ainda que tenha feito muitas amizades indianas. $O$ fato é que hoje tenho mais amigos indianos que Tibetanos. Agora vivo aqui nos Himalaias, na estação-colina chamada Dharamsala, o local que a Vossa Santidade chama de lar. Venho à Mumbai por causa de uma variedade de trabalho relacionado ao Tibete e, sempre que venho, tenho vários amigos anfitriões para encontrar. Posso ficar e comer em qualquer lugar em Mumbai. Sinto-me muito comfortável com a maneira de pensar do pessoal de Mumbai, a sua língua, a sua cultura e a atitude chalta hai (“despreendida"). Por tudo isso, sinto-me em casa em Mumbai.

Mumbai simpatiza com a causa Tibetana. Em 2002, quando o primeiro ministro chinês Zhu Rongji visitou a cidade, fiz palco a um protesto escalando as galerias do Hotel Oberoi (hoje em dia, Hilton). Do décimo quarto andar, estendi uma faixa que dizia "Tibete Livre". Recebemos a atenção da mídia internacional, mas nada à altura de manchete da capa principal em Mumbai e, na sequência, o apoio do público. Subitamente, Bombai fez um x no mapa do movimento de liberdade do Tibete. Tive que ficar na estação policial Cuffe Parade até tarde da noite, mas, para mim, aquele foi o momento mais memorável em Mumbai.

Entretanto, se não tornássemos o movimento de liberdade forte a partir da comunidade tibetana, nenhum apoio substancial poderíamos obter. Para tanto, eu precisava estar trabalhando dentro da comunidade Tibetana. Por isso, mudei-me de Mumbai, ainda que apenas fisicamente. O meu sonho é livrar o Tibete da ocupação chinesa e reconstruir o nosso lar por lá. Até lá, poderei estar em qualquer canto, mas nunca terei um lar. Legalmente, somos um povo sem país, incluindo-se o próprio Dalai Lama. O lar tem um significado muito sagrado para mim. Amanhã, quando regressarmos ao Tibete após a nossa independência, ainda voltarei à amchi/nossa Mumbai.

Certa vez, eu levava uma carta de um amigo a sua velha mãe. Não pude entregá-la no dia da minha chegada. Logo cedo na manhã seguinte, um amigo me 
disse que a mãe havia morrido na noite anterior em seu próprio sono. Ela tinha 79 anos. E costumava falar conosco, jovens, sobre a sua vida no Tibete. Dispendi longas horas ouvindo a sua estória de vida. E costumava lhe dizer que o Tibete iria logo se tornar livre e que todos nós poderíamos regressar ao lar. Cremamo-la no crematório público de Chandan Wadi. No ano anterior, enterramos um velho Tibetano, de 80 anos, no cemitério de Dadar.

Estamos perdendo a nossa geração mais velha rapidamente, a geração mais velha dos que habitaram o Tibete e testemunharam a invasão chinesa, de maneira que logo não haverá mais nenhum de nós para ver o Tibete livre e poder nos dizer como era a vida antes dos chineses terem avançado. Até que ganhemos a nossa terra de volta, temos de passar as nossas estórias e canções de geração a geração, enquanto moramos em Mumbai - longe dos nossos lares nas montanhas.

Dharamsala, Janeiro de 2006

Gisele Wolkoff é autora de Ar (2016) Rumo ao Sol(2014) e Partidas (2012) publicados pela Editora Palimage em Portugal, e professora da Universidade Federal Fluminense, onde coordena pesquisa na área de Literatura, Cultura e Tradução. Organizou e traduziu Plurivozes Americanas/American Plural Voices/Plurivoces Amercanas (Curitiba, CRV: 2015) e Ten Contemporary Irish and Portuguese Women Poets (Coimbra, Palimage: 2011). 